\title{
Sustainability in business models in the network economy
}

\author{
Marek Jabłoński ${ }^{1}$ (1) $\cdot$ Paul Timmers ${ }^{2} \cdot$ Joseph Sarkis ${ }^{3,4}$ \\ Received: 12 October 2020 / Accepted: 12 October 2020/ Published online: 16 October 2020 \\ (C) Institute of Applied Informatics at University of Leipzig 2020
}

\section{Dear Readers of Electronic Markets,}

The network economy is giving rise to many new business models. The dynamic development of networking is influenced by the fast-paced evolution — some might say revolution - of digital technologies. The development of business models depends on the environment in which the enterprise operates and the specificity of the business ecosystem (Alt 2020). The issue of sustainability in business models in the network economy is currently particularly important. Companies are increasingly expected to positively contribute to life of people, to the wider economic and societal ecosystem, and to the protection of our natural resources, combatting climate change; all of which are considered in the wider sustainability of our planet.

These changing expectations and the evolution in the network and digital economy imply the pertinent need for a broad and open discussion and discourse. This important conversation is needed to develop new perspectives - based on rigorous scholarship and theoretical foundations - to identify the determinants of enterprise management and business models in this sustainability context. The sustainability context includes a balance of multiple measures.

This article is part of the Topical Collection on Sustainability in business models in the network economy

Marek Jabłoński

marek.jablonski@ottima-plus.com.pl

Paul Timmers

paultimmers@gmail.com

Joseph Sarkis

jsarkis@wpi.edu

1 Faculty in Chorzów, WSB University in Poznan, Chorzów, Poland

2 Centre for Technology and Global, University of Oxford, Affairs Manor Road, Oxford OX1 3UQ, UK

3 Foisie Business School, Worcester Polytechnic Institute, Worcester, MA, USA

4 Hanken School of Economics, Humlog Institute, Helsinki, Finland
In recent years, digitally-enabled business models and electronic markets are designed within the context of institutional and social change posed by social innovations such as the circular economy and the sharing economy. A key issue for digital business model design in this dynamic socio-economic and ecological environment thus is achieving sustainability in a balanced, inclusive, and equitable way.

Similarly, science is looking for theories that will help to understand what factors are important to ensure the success of companies - and their network partners - when operating in a digital economy. In recent years, scholars have become increasingly interested in the concept of sustainability in the context of digitization and digital companies (Ghobakhloo 2020). The concept of sustainable business has been part of the discourse for several years in the International Journal of Electronic Markets (EM). The analysis of articles connected with topics "Sustainable" and "Sustainability" in the period from 2009 to 2020 shows an upward trend with significant positive increases after 2017. This means that the configurations of business models and the scope of activities of digital companies are more and more often considered through the prism of the concept of sustainable development.

The analysis of the content of articles published in $E M$ as well as in conference materials of the Bled eConference, an important harbinger of emerging study within the scientific community, shows a growing trend on the relationships between sustainability the functioning and development of digital companies, their supply chains, products and materials.

An analysis of 211 articles from EM and 356 articles from Bled eConference showed that digital transformation can be shaped with explicit considerations of social impact. It is important in the context of challenges and humanizing technologies for a sustainable society. Recently the special interest tracks on these topics have grown across multiple disciplines related to information and automation technology. Topics that would have strong sustainability implications include e-digital health, e-digital wellbeing, social media, blockchain technologies, data science, big data, education and learning in the digital society, smart, sustainable cities and business models. Each of these topics and relationships concern some element 
of sustainable development and sustainable performance (Pucihar 2020).

We must also be wary of the reductionist approach of these topics and the science in these areas. Sustainability should not be separable and investigated in scientific silos considering only one type of technology and only one dimension of sustainability. Sustainability and its social innovations are necessarily systemic and networked. Trying to evaluate and study only a focused topic without recognizing a broader holistic series of interactions that can potentially co-exist, could cause more harm than good. There needs to be both a call for new and insightful, rigorous research on broader markets, business models, and networks.

The creation of this Special Issue originated from observations about the state of play in research on sustainability and business models. The concept of value based management, myopic profit seeking goals, and other short term corporate decision making has not proven to be successful and has led to detrimental relationship of cooperation between enterprises and stakeholders other than shareholders (Martin et al. 2009).

There was and remains a need find new ground for discussions on the network approach to shaping the strategy of sustainable business. We also noted a great interest of researchers in the influence of the network economy on the development of the circular economy concept, as well as the design of modern supply chains. The latter has become even more pertinent with the Covid 19 pandemic with its pressure to shorten and re-shore supply chains, which may lead to more local and less global impact of business models (Sarkis et al. 2020). The role of supply chains in the network economy is therefore of key importance for the theme of sustainability. The special issue also set out to address the trend that the network economy is increasingly assessed form the perspective of the Circular Economy.

The topics discussed in this Special Issue on 'Sustainability in business models in the network economy' confirm these trends in the concept of sustainability, especially in the context of applying it to the design and use of business models with specific pro-socio-environmental features.

In current theory and practice at least three approaches to sustainability may be distinguished.

1. First is the Triple Bottom Line (TBL). TBL is often used by organizations who create a sustainability strategy using stakeholder analysis, corporate social responsibility (CSR) activities, and seeking win-win-win opportunities. Business models seek a balance of ecological, social and economic factors. TBL can be a differentiator providing a competitive advantage for companies. For example, organizations can build a business case by including ecologically friendly products in their product portfolios, undertaking activities for positive impact on environmental protection, and striking a balance amongst stakeholder interests. The business case can also include improving image, brand and reputation of organizations. The circular economy is a policy adopted by many countries throughout the world, seeking to balance sustainability at a broader regional and national level. The circular economy is a driver for innovation in the areas of material-, component- and product reuse, as well as an enabler for such new TBL business models. In a circular economy, waste is 'food' and can be utilized in creative ways meaning there are significant opportunities for new business and social entrepreneurship.

2. The second approach is based on assumptions of business model for sustainability. In this holistic approach 'no sustainable value can be created for customers without creating value to a broader range of stakeholders' (LüdekeFreund 2010; Schaltegger et al. 2016; Boons et al. 2013). This also includes a management approach which aims at achieving success in a fair manner for employees. This topic is widely developed in the literature; and focuses strongly on the social dimensions of sustainability.

3. The third approach addresses the specific aspect of economic sustainability in combination with the emerging shared economy business models that are enabled by a networked economy. Very important for the sustained continuity of these business models is to consider issues such as social, ecological, and labor rules, which may be captured in legal requirements but also in social norms and values. The concept of the shared economy is becoming more prevalent due to the networked society and the "Internet of Things". The sharing economy is a socioeconomic ecosystem built around the sharing of human, physical and intellectual resources. It includes the shared creation, production, distribution, trade and consumption of goods and services by different people and organizations.

Sustainability for building competitive advantage is also an ethical approach for building markets, supporting innovative solutions that have a positive impact on society, creating social value and social profit. Essentially it relates to the mantra of 'doing well, by doing good'. In general, various archetypes of sustainable business models are currently being created, which are also adequate for the challenges of the digital economy (Bocken et al. 2014; Centobelli et al. 2020).

The subject of this special issue is then to analyze how to incorporate sustainability into business and e-business models. A basic question is whether this integration will allow companies to gain competitive advantage in a just way while helping organizations thrive. Part of this long-term competitive perspective includes to increase organizational market valuations and the creation of strong brands. In modern business models, classical economics provides only a partial answer: with the emergence of the sharing economy and the 
circular economy, the classical non-cooperative rent-seeking economic pressures will need to be reconsidered.

The three scientific articles published in this Special Issue all deal with the issue of sustainability as a business model. The three studies provide guidelines for other researchers on how to research and evaluate business models from a balanced approach to shaping social and environmental policies and business ethics in ta network economy.

We briefly present the three papers here:

- Implementation of Triple Bottom Line to a Business Model Canvas in Reverse Logistics by Wit and Pylak 2020 presents the business model concepts combining sustainable development and risk management in reverse logistics value chains for hazardous waste. The authors develop a novel sustainable business model canvas for both an entity and the logistics system using Osterwalder's Business Model Canvas integrated with the concept of sustainable development in economic, social and environmental (TBL) areas and risk-related elements. The model was implemented in the prototype of computer software in the form of electronic network services.

The model has strong theoretical and practical foundations. It provides a multi-layered perspective including the many holistic dimensions that are missing in many studies on business models. TBL, supply chain, and business model theoretical dimensions are presented to a very important environmental, health and safety concern. The primary supply chain aspect is logistics. Their evaluation and testing of their business model using the various complex measures and dimensions is a very unique methodology that can serve as a wonderful holistic evaluation of these complex relationships.

- When does it pay off to integrate sustainability in the business model? - A Game-Theoretic Analysis by Gimpel et al. 2019 analyses answers by applying a game-theoretic framework and examining competition strategies for organizations integrating sustainability in their business model. The authors consider different market scenarios where symmetric and asymmetric, weak and strong, as well as a varying number of organizations interact. Their results suggest different strategies organizations can apply to gain competitive advantage. This article addresses the specific aspect of economic sustainability in combination with the business models that are enabled by a networked economy.

In their article, similar to Wit and Pylak in this special issue, the clearly identify the multiple factors and complexity with balancing business models with the sustainability dimensions. In a rigorous presentation, they provide some results that show when different companies should adopt sustainable business models. Although limited by the theoretical capabilities of the models, and simplifying assumptions, their contributions along can further and rigorously support other models and approaches. We do recommend that information from multiple sources including this rigorous study can provide significant practical and theoretical support for the timing and conditions that organizations adopt sustainability practices. This study also allows for consideration of further dynamics; something that the next article also touches upon, but from another interesting and different methodological approach than the other two articles in this special issue.

- Dynamic, network and resource-based approach to the sustainable business model: a study of a virtual reality company by Ujwary-Gil and Potoczek 2020. The authors analyzed the influence exerted by a key node that has been eliminated from the network on the remaining structure, based on the immediate impact (change analysis), which computes the key nodes of the network and then isolates them individually to determine the effect on measured values. The primary research approach is an organizational network analysis - mostly centrality measures - and a simulation functionality used for determining measures and visualization, before and after changes. The results indicate the level of centrality measures of all nodes in the network (a virtual reality company's business model), their interdependence, and the dynamics of their change. The paper concludes with implications for theory and practice, limitations, and directions for further research. This article presents sustainability from the perspective of a network of relations. The components based on TBL support the shaping of a business model.

Once again, their underlying theme is what we had expected in the papers that were published in this special issue, but also covered in other related fields such as circular economy and sustainability supply chains. That is, the issue of complexity. The company in this paper is not one that most would come to mind when a sustainability business model is presented, which makes it even more unique and broadens the perspectives of what companies can be sustainability. As mentioned, they consider a virtual reality company. Whereas the first paper clearly identified hazardous waste reverse logistics models - where sustainability concerns are paramount this one considers one not typically associated with sustainability. It also considers whether the competitiveness and network structure differ and how it affects the business model.

A very unique data set is used in this study for evaluation. Seven major categories and multiple sub-dimensions are used to define the business model for a virtual reality company. These dimensions of the business model are formed into a network of relationships amongst the sub-factors. The 
implications of sustainability show the possibility of integrating a variety of environmental, social (people), and economic resources and outputs from a business perspective. The shifts in relationships with their model can provide more depth to the holistic outcomes, both expected and unexpected as various factors gain or wain in importance. Although in this case business sustainability focused more on the long run economic dimensions.

These findings provide additional foundation and building valuable contributions to sustainability in the digital economy literature. This literature requires significantly more research that balances scientific and theoretical rigor with practical implications to actually solve real-world problems.

We hope that our special issue provides insights for developing and implementing sustainability in a digital and networked economy in academic and practical settings.

- Marek Jabłoński, WSB University in Poznan, Faculty in Chorzów, Poland.

- Paul Timmers, Oxford University research associate, adjunct professor European University Cyprus, advisor on technology, policy, economy \& society, Belgium.

- Joseph Sarkis, Foisie Business School, Worcester Polytechnic Institute, USA.

\section{References}

Alt, R. (2020). Electronic markets on business model development. Electronic Markets, 30(3), 405-411. https://doi.org/10.1007/ s12525-020-00438-Z.

Bocken, N. M. P., Short, S. W., Rana, P., \& Evans, S. (2014). A literature and practice review to develop sustainable business model archetypes. Journal of Cleaner Production, 65, 42-56. https://doi.org/10. 1016/j.jclepro.2013.11.039.

Boons, F., Montalvo, C., Quist, J., \& Wagner, M. (2013). Sustainable innovation, business models and economic performance: An overview. Journal of Cleaner Production, 45, 1-8. https://doi.org/10. 1016/j.jclepro.2012.08.013.
Centobelli, P., Cerchione, R., Chiaroni, D., Del Vecchio, P., \& Urbinati, A. (2020). Designing business models in circular economy: A systematic literature review and research agenda. Business Strategy and the Environment, 29(4), 1734-1749. https://doi.org/10.1002/bse. 2466.

Ghobakhloo, M. (2020). Industry 4.0, digitization, and opportunities for sustainability. Journal of Cleaner Production, 252, 119869. https:// doi.org/10.1016/j.jclepro.2019.119869.

Gimpel, H., Graf-Drasch, V., Kammerer, A., Keller, M., \& Zheng, X. (2019). When does it pay off to integrate sustainability in the business model? - A game-theoretic analysis. Electronic Markets, 30(4). https://doi.org/10.1007/s12525-019-00361-y.

Lüdeke-Freund, F. (2010). Towards a conceptual framework of 'Business models for Sustainability', Conference: Knowledge Collaboration \& Learning for Sustainable Innovation“ - Conference Proceedings, 14th European Roundtable on Sustainable Consumption And Production (ERSCP) \& 6th Environmental Management for Sustainable Universities (EMSU), 25-29 October 2010, At Delft, The Netherlands.

Martin, J. D., Petty, J. M., \& Wallace, J. S. (2009). Value based management with corporate social responsibility. Oxford: Oxford University Press.

Pucihar, A. (2020). The digital transformation journey: Content analysis of electronic markets articles and bled eConference proceedings from 2012 to 2019. Electronic Markets, 30(1), 29-37. https://doi. org/10.1007/s12525-020-00406-7.

Sarkis, J., Cohen, M. J., Dewick, P., \& Schröder, P. (2020). A brave new world: Lessons from the COVID-19 pandemic for transitioning to sustainable supply and production. Resources, Conservation, and Recycling, 159, 104894. https://doi.org/10.1016/j.resconrec.2020. 104894.

Schaltegger, S., Lüdeke-Freund, F., \& Hansen, E. G. (2016). Business models for sustainability a co-evolutionary analysis of sustainable entrepreneurship, innovation, and transformation. Organization \& Environment, 29(3), 264-289. https://doi.org/10.1177/ 1086026616633272.

Ujwary-Gil, A., \& Potoczek, N. R. (2020). A dynamic, network and resource-based approach to the sustainable business model. Electronic Markets, 30(4). https://doi.org/10.1007/s12525-02000431-6.

Wit, B., \& Pylak, K. (2020). Implementation of triple bottom line to a business model canvas in reverse logistics. Electronic Markets, 30(4). https://doi.org/10.1007/s12525-020-00422-7.

Publisher's note Springer Nature remains neutral with regard to jurisdictional claims in published maps and institutional affiliations. 